\title{
Evaluation of the Effectiveness of Fungi (Candida Tropicalis and Aspergillus Clavatus) in Bioremediation of used Engine Oil Contaminated Soil using Bioaugmentation Technique
}

\author{
Mbachu, Augustine Ebele ${ }^{1 *}$, Chukwura, Edna Ifeoma ${ }^{1}$, and Mbachu, Nancy \\ Amalachukwu ${ }^{2}$
}

\begin{abstract}
${ }^{1}$ Department of Applied Microbiology \& Brewing, Faculty of Biosciences, Nnamdi Azikiwe University, Awka, Nigeria. ${ }^{2}$ Department of Human Biochemistry, Faculty of Basic Medical Sciences, Nnamdi Azikiwe University, Nnewi campus, Nigeria.

*Corresponding author; email: ebelembachu@yahoo.com
\end{abstract}

\begin{abstract}
Used engine oil is a petroleum or synthetic oil that has been used and as a result of such use, is contaminated by physical and chemical pollutants. These pollutants are harmful to humans, animals and plants following exposure. Evaluation of the effectiveness of fungi in bioremediation of used engine oil (UEO) contaminated soil was investigated. Fungi were isolated from soil samples obtained from automobile workshops in Mgbuka-Nkpor, Nigeria. The isolates were screened for UEO biodegradation potentials in mineral salt broth. They were identified using the cultural and microscopic characteristics and confirmed using the 18SrRNA gene sequence. The effectiveness of the isolates in bioremediation of UEO contaminated soil was also investigated using bioaugmentation technique. A total of 8 fungal isolates were obtained from this study. Two that showed the highest extent of biodegradation of UEO in the screen flasks were identified and confirmed as Candida tropicalis and Aspergillus clavatus. At the end of the experimental period, oil contaminated soil inoculated with the mixed culture of the isolates (C. tropicalis and A. clavatus) showed the highest reduction in concentration of UEO (95.42\%). Higher biodegradation rate and shorter halflife of total petroleum hydrocarbon (TPH) was observed in soil microcosm containing the isolates, when compared to the uninoculated control. Therefore fungi such as $C$. tropicalis and A. clavatus isolated from automobile workshops can facilitate the bioremediation of UEO contaminated soil.
\end{abstract}

Keywords- Aspergillus clavatus, bioremediation, bioaugmentation, Candida tropicalis, used engine oil.

\section{INTRODUCTION}

The petroleum hydrocarbons are hazardous to various forms of terrestrial and aquatic life like fish, bird and human, and are also carcinogenic, mutagenic and potentially immunotoxigenic [1]. Indiscriminate disposal of used engine oil into gutters, water drains, open vacant plots and farmlands, has led to contamination of soil with hydrocarbons, resulting in serious hazardous effects to human health, animals and plants, as well as pollution of groundwater, which has limited its use. The traditional physical and chemical treatment approaches to clean up the petroleum hydrocarbons are expensive and appear ineffectual as they do not lead to complete mineralization, and awfully can produce toxic byproducts or residues. In contrast, as an innovative and eco-friendly strategy, bioremediation involving microbial agents, such as protozoa, bacteria, fungi, plants offers successfulalternatives to clean-up the petroleum pollution [2]. Biological methods can have the edge over these treatments in removing oil spills. Bioremediation technology is a safe, economical, more efficient, reliable method that is harmless and ecofriendly [3, 4].

Many microorganisms such as bacteria, fungi, and yeast use their enzymatic activity to utilize hydrocarbons as a sole carbon source $[4,5,6]$. Among fungal bioremediating agents, mold species of Aspergillus, Penicillium, Fusarium, Amorphoteca, Paecilomyces, and Talaromyces, and yeast species of Candida, Yarrowia, and Pichia have been recognized in hydrocarbon degradation and its derivatives [7, 8]. Fungi have advantages over other microorganisms in that they produce classes of enzymes that can interact with several types of polycyclic aromatic hydrocarbons with a 
fairly high degree of non-specific activity. Fungi are also tolerant to high concentrations of recalcitrant compounds and are able to flourish in extreme conditions. Some recent studies have reported the use of a mixed population of fungal strains that could enhance biodegradation efficiency, especially on high concentrations of oil [6,9].

Bioaugmentation is an approach that involves introduction of microorganisms that possessed biodegradation potentials into the contaminated environment to assist the indigenous microbes with biodegradative processes [10]. Bioaugmentation has several advantages over other techniques [11]. When a specific microbial population is injected, the degradation process can start immediately, while biostimulation, for instance, involves a delay after injection of nutrients as the microbial population propagates and also nutrient are not specific, so that all microbes will potentially propagate, diluting the effect of the nutrients [11]. The present study aims to evaluate the effectiveness of fungi $C$. tropicalis and $A$. clavatus in bioremediation of used engine oil contaminated soil using bioaugmentation technique.

\subsection{Collection of Samples}

\section{MATERIALS AND METHODS}

Soil samples were collected randomly using a precleaned hand scoop at a depth of $0-3 \mathrm{~cm}$ from 3 automobile workshops at Old Motor Spare Parts popularly called Mgbuka-Nkpor (609'N 6050'E), Nigeria. Uncontaminated soil samples were also collected randomly from a fallow plot of land about $100 \mathrm{~m}$ from contaminated sites, and placed in a sterile container. Used engine oil (UEO) used in this study was collected direct from the engine of 911 Lorry $[12,13]$ at Mgbuka-Nkpor. Samples were transported in cold storage container to the Microbiology Laboratory of the National Agency for Food and Drug Administration and Control (NAFDAC), Agulu, Nigeria, for analysis.

\subsection{Isolation of fungi from used engine oil contaminated soil}

The mold Aspergillus sp and yeast Candida sp were isolated from the soil samples obtained from automobile workshops (at Mgbuka-Nkpor, Nigeria) on mineral salt medium of Zajic and Supplission [14], with composition $(\mathrm{g} / \mathrm{L}) ; \mathrm{K}_{2} \mathrm{HPO}_{4}, 1.8 ; \mathrm{KH}_{2} \mathrm{PO}_{4}, 1.2 ; \mathrm{NH}_{4} \mathrm{Cl}, 4.0 ; \mathrm{MgSO}_{4} .7 \mathrm{H}_{2} \mathrm{O}$, $0.2 ; \mathrm{NaCl}, 0.1 ; \mathrm{FeSO}_{4} .7 \mathrm{H}_{2} \mathrm{O}, 0.01$ and agar, 15 g. Fifty micrograms per millilitre $\left(50 \mu \mathrm{g} \mathrm{mL}^{-1}\right)$ of each of penicillin $\mathrm{G}$ and streptomycin was incorporated into the medium to inhibit interfering bacteria. The medium $\mathrm{pH}$ was adjusted to 5.5. The whole preparation was autoclaved, distributed into sterile petri dishes and allowed to solidify. One gramme of the homogenized soil sample was measured into $9 \mathrm{ml}$ of sterile distilled water in a test tube and swirled gently. $1 \mathrm{ml}$ of the sample was pipetted and serially diluted up to $10^{-3}$ dilution. $0.1 \mathrm{ml}$ of the sample from the $10^{-2}$ and $10^{-3}$ dilutions were transferred onto the surface of a freshly prepared mineral salt agar using the spread plate technique [15]. A Whatman No. 1 filter paper saturated with sterilized used engine oil was placed inside the lid of the plates. The plates were incubated at $28^{\circ} \mathrm{C}$ for 7 days. Each distinct colony on oil degrading enumeration plates were purified by repeated sub culturing onto the surface of a freshly prepared Sabouraud Dextrose Agar (SDA) (Merck, Germany) plates to obtain pure cultures of the isolates. The pure cultures were maintained on SDA slants.

\subsection{Screening test for UEO biodegradation potentials of the fungal isolates}

The isolates were screened for used engine oil biodegradation potentials on mineral salt broth using the method of Olajide and Ogbeifun [16], with determination of $\mathrm{pH}$ and total viable count at time intervals as biodegradation indices. The residual hydrocarbon was also determined at time interval using the Spectrophotometric method [17].

\subsection{Identification of the isolates}

The cultural characteristics of the pure isolates on SDA were noted, and the microscopic features were observed using the wet mount and the microslide culture technique with reference to the Manual of Fungal Atlas $[18,19]$. The isolates were also confirmed using 18S rRNA gene sequence.

\subsection{Evaluation of the effectiveness of the isolates in bioremediation of UEO contaminated soil.}

To evaluate the effectiveness of the isolates in bioremediation of UEO contaminated soil, soil microcosms were prepared in $250 \mathrm{ml}$ Erlenmeyer flask using mineral salt broth. One hundred grammes $(100 \mathrm{~g})$ of the uncontaminated soil samples were added into $60 \mathrm{ml}$ of mineral salt broth in $250 \mathrm{ml}$ Erlenmeyer flask. The slurries obtained were spiked with $5 \mathrm{~g}$ of sterile UEO simulating a soil contamination corresponding to $50,000 \mathrm{mg} \mathrm{kg}^{-1}$ soil.

Bioaugmentation was carried out by inoculating 10 $\mathrm{ml}$ of standard inocula $(\mathrm{OD}=1.0)$ of each of the pure and mixed culture of the isolates (C. tropicalis and A. clavatus) into the flasks. Treatment with only soil and UEO served as control 1. Additional control 2 was also set up which contained autoclaved soil and sterile UEO to monitor abiotic loss of oil in the oil-contaminated soil. The flasks were 
incubated in triplicate in an Orbital Shaker at $120 \mathrm{rpm}$ and $28^{\circ} \mathrm{C}$ for 56 days. The total petroleum hydrocarbon (TPH) content of the flasks was determined at $0,14,28,42$ and 56 days, using Spectrophotometric method [17]. TPH data were fitted to the first-order kinetic model [20]:

$\mathrm{C}=\mathrm{Coe}^{-k t}$, where $\mathrm{C}$ is the hydrocarbon content in soil $(\mathrm{mg}$ $\mathrm{kg}^{-1}$ ) at time $\mathrm{t}, \mathrm{Co}$ is the initial hydrocarbon content in soil $\left(\mathrm{mg} \mathrm{kg}^{-1}\right), k$ is the biodegradation rate constant $\left(\mathrm{day}^{-1}\right)$, and $t$ is time (day). The model estimated the biodegradation rate and half-life of hydrocarbons in soil relative to treatments applied. Half-life was then calculated from the model of Yeung et al. [21]. Half-life $=\ln (2) / k$, where $\ln (2)$ is the natural logarithm of 2 (approximately 0.693).

The effectiveness of the isolates in remediation of used engine oil contaminated soil was also determined by calculating the net percentage loss of TPH in the oil contaminated soil, using the formula: Net $\%$ loss $=\%$ loss of TPH in soil microcosm inoculated with the isolates - \% loss of TPH in uninoculated soil microcosm (ie. control 1).

\subsection{Statistical Analysis}

Data were analysed and presented as mean \pm standard deviation (SD) of three replicates. The Student's t-test was used to test the significance of difference between the mean values. A statistical package for social sciences (SPSS) software was used for statistical analysis in this study and test for significance between means was implied at $\mathrm{P}=0.05$ level.

\section{RESULTS}

\subsection{Isolation and screening of UEO degrading fungi}

A total of eight hydrocarbon utilizing fungi (labeled A-H) were isolated from soil samples obtained from used engine oil contaminated soil. The relationship between $\mathrm{pH}$, TVC and oil loss were shown in Figures 1 to 3. Generally, a decreasing trend in $\mathrm{pH}$ was observed in the experimental flasks within the incubation period, with a concomitant decrease in hydrocarbon levels, as growth (TVC) increases. However, the decreasing trend in $\mathrm{pH}$ was more evident in the experimental flasks containing isolate A and D (Fig. 1). Moreover, there was an increase in total viable count (TVC) from 0 to 12 days, with a slight decrease on the $16^{\text {th }}$ day (Fig. 2 ), in all the experimental flasks. The hydrocarbon losses were higher $(>70 \%)$ in the flasks containing isolate A and D while the hydrocarbon losses in the flasks containing isolates $\mathrm{B}, \mathrm{C}, \mathrm{E}, \mathrm{F}, \mathrm{G}$ and $\mathrm{H}$, were lower $(<70 \%)$ within the experimental period (Fig. 3). In the control flasks, no growth was observed within the experimental period, with no significant oil loss and $\mathrm{pH}$ change (Figs. 1 to 3). Based on these observations, isolates A and D were selected for further studies.

\subsection{Identification of the isolates}

Based on their cultural and microscopic characteristics, isolate A was identified as yeast belonging to the genus Candida sp while isolate D was identified as mold belonging to the genus Aspergillus sp. To confirm the results of the cultural and microscopic identification of the isolates, the 18S rRNA gene sequence of the isolates were determined. Database comparism using BLAST program revealed that the yeast isolate had a high similarity of $98 \%$ with those of Candida tropicalis. However, the mold isolate had $100 \%$ similarity with those of Aspergillus clavatus. The expected values (E-value) for the isolates are zero.

\subsection{Evaluation of the effectiveness of the isolates in} bioremediation of UEO contaminated soil.

\subsubsection{Biodegradation of used engine oil contaminated soil}

The level of biodegradation of used engine oil throughout the experimental period is shown in Figure 4. There was a rapid reduction in the TPH within the first 14 days of the study in the soil microcosm inoculated with the pure and mixed culture of the isolates compared to the uninoculated control. At the end of the experimental period (56 days), oil contaminated soil inoculated with the mixed culture of the isolates (C. tropicalis and A.clavatus) showed the highest reduction in concentration of used engine oil (95.42\%). This was followed closely by 90.63 and $90.42 \%$ reduction in soil microcosm inoculated with the pure cultures of A. clavatus and C. tropicalis, respectively. Uninoculated control 1 showed $54.17 \%$ reduction at the end of the experimental period. Moreover, there was $4.0 \%$ abiotic loss in the autoclaved soil containing sterile used engine oil (i.e., control 2) at the end of the experimental period.

\subsubsection{The Net Percentage (\% ) Loss of TPH in Soil during Bioremediation}

As shown in Table 1, the highest net percentage loss of TPH was observed at 14 day in the soil microcosm containing the pure and mixed culture of the isolates. However, it was observed that the net percentage loss of TPH in soil inoculated with both the pure and mixed culture of the isolates decreased from 14 day throughout the experimental period. Moreover, the net percentage loss in soil inoculated with the mixed culture of the isolates was higher throughout the experimental period (from 14 to 56 days), when compared to the single cultures. 


\subsubsection{Biodegradation Rate Constant and Half-Life}

Table 2 shows the biodegradation rate constant $(k)$ and half-life $\left(t_{1 / 2}\right)$ for the different soil microcosms within the experimental period. Soil inoculated with the mixed culture of the isolates showed the highest biodegradation rate $\left(\right.$ day $\left.^{-1}\right)$ and lowest half-life (days), while the uninoculated soil (control) showed the lowest biodegradation rate $\left(\mathrm{day}^{-1}\right)$ and highest half-life (days).

\section{DISCUSSION}

The species of some of the isolates used in this study have earlier been reported as hydrocarbon degraders [22]. George-Okafor et al. [8] reported the isolation of Aspergillus spp., Syncephalastrum spp., Trichoderma spp., Neurospora sitophila, Rhizopus arrhizus, Mucor spp. and yeast species of Candida, Yarrowia, and Pichia from petroleum contaminated soil.

The decreasing trend in $\mathrm{pH}$ observed during the screening test in this study could be as a result of mineralization of hydrocarbons in used engine oil by the isolates. This was in agreement with the findings of Olajide and Ogbeifun [16], who reported a decreasing trend in $\mathrm{pH}$ during hydrocarbon degradation by Proteus vulgaris. Sepahi et al. [23] reported that microbial degradation of hydrocarbons often leads to production of organic acids, thus the organic acids probably caused the reduction in $\mathrm{pH}$.

The increase in the growth (TVC) of the isolates in the media containing used engine oil could be attributed to the ability of the organisms to utilize UEO as a sole source of carbon. It could also be that the cultural condition was adequate for the growth of the organisms. This was in agreement with the findings of Vanishree et al. [24] who reported that several fungal isolates such as Fusarium solani, Fusarium oxysporium, Trichoderma viride and Aspergillus niger cultured in mineral salt medium (MSM) at $\mathrm{pH} 5.5$ showed good growth. The decrease in the growth of the isolates on the $16^{\text {th }}$ day could be due to the decrease in $\mathrm{pH}$ level. It could be that the $\mathrm{pH}$ became too acidic for the organisms to thrive. It could also be as a result of decrease in substrate (UEO) used by the organisms as a sole source of carbon and energy. The findings of Obire and Nwaubeta [25] who reported an initial gradual increase in the bacterial population following the application of petroleum hydrocarbon but a decline as the biodegradation progressed supports this explanation. Similarly, Akpoveta et al. [17] reports that hydrocarbon degrading fungi increased within the first seven days from $2.16 \times 10^{4} \mathrm{cfu} / \mathrm{g}$ to $11.1 \times 10^{4} \mathrm{cfu} / \mathrm{g}$ and decreased progressively to $1.5 \times 10^{4} \mathrm{cfu} / \mathrm{g}$ within the next four weeks. A decrease in substrate will therefore result in a drop in the population of oil-degraders.

The higher net percentage (\%) loss of TPH in UEO observed in the soil microcosm inoculated with the mixed culture suggested that the isolates could co-exist with no adverse effect and possibly have a synergy, which may be responsible for the higher net $\%$ loss of oil observed in this study. The advantages of employing mixed cultures have been reported [26, 27]. Ghazali et al. [28] reported that some species are able to remove the toxic metabolites that prohibit the activities of the other species. Then it is possible that the other species degrade complex compounds totally.

High biodegradation rate and low half-life observed in soil microcosm inoculated with the mixed culture of the isolates could be attributed to the high net loss (\%) of TPH throughout the experimental period. However, the higher biodegradation rate and lower half-life observed in soil microcosm inoculated with both the single and mixed culture of the isolates compared to the uninoculated control could be due to the previous exposure of the isolates to soil contaminated with UEO. It was speculated that native strains of oil contaminated soil already shaped by selective pressure, could take advantage with respect to sensitive strains in accomplishing biodegradation of hydrocarbon polluted environment. This way, they could help to overcome an important limitation in bioremediation applications such as the toxic effect of petroleum hydrocarbons, which inhibit biodegradation process [29].

\section{CONCLUSION}

Bioaugmentation with the fungal isolates enhanced the remediation of used engine oil contaminated soil as reflected in the biodegradation constant and half life of the total petroleum hydrocarbon observed in the soil microcosm containing the isolates, when compared to the uninoculated soil microcosm. This bioaugmentation strategy may contribute to overcome a critical bottleneck of the bioremediation technology. Finally, fungi such as $C$. tropicalis and A. clavatus, isolated from automobile workshops can efficiently facilitate the bioremediation of used engine oil contaminated soil.

\section{REFERENCES}

[1] Dhar K., Dutta S. and Anwar M.N. (2014). Biodegradation of petroleum hydrocarbon by indigenous fungi isolated from Ship breaking yards of Bangladesh. International Research Journal of Biological Sciences, 3(9): 22-30. www.isca.in, www.isca.me. 
[2] Bento F.M., Camargo F.A.O., Okeke B.C. and Frankenberger W.T. (2005). Comparative bioremediation of soils contaminated with diesel oil by natural attenuation, biostimulation and bioaugmentation, Bioresource Technology, 96, 10491055.

[3] Prakash B. and Irfan M. (2011). Pseudomonas aeruginosa is present in crude oil contaminated sites of Barmer Region, India. Journal of Bioremediation \& Biodegradation, 2(5): 129 . doi:10.4172/21556199.1000129.2.

[4] Hidayat A. and Tachibana S. (2012). Biodegradation of aliphatic hydrocarbon in three types of crude oil by Fusarium sp. F092 under stress with artifi cial sea water. Journal of Environmental Science and Technology, 5(1): 64.

[5] Khaled M. G, Saleh M.A. and Majid A.A. (2016). Bioremediation of diesel fuel by fungal consortium using statistical experimental designs. Pollution Journal of Environmental studies, 25(1): 97-106. DOI: 15244/pjoes/42493.

[6] Martin Y.B., Acosta S., Sanchez A., Toledo A., Gonzalez F. and Garcia R.M. (2012). Study and isolation of aerobic hydrocarbon-degrading bacteria from Cuban shorelines. Biotechnologia Aplicada. 29, 80.

[7] Chaillan, F., le Fleche, A., Bury, E. Phantavong, Y.H., Grimont, P., Saliot, A. and Oudot, J. (2004). Identification and biodegradation potential of tropical aerobic hydrocarbon-degrading microorganisms. Research in Microbiology, 155: 587595.

[8] George-Okafor, U., Tasie, F. and Muoteo-Okafor, F. (2009). Hydrocarbon degrading potentials of indigenous fungal isolates from petroleum contaminated soils. Journal of Physical and Natural Sciences, 3 (1): 1-6.

[9] Malik Z.A. and Ahmed S. (2012). Degradation of petroleum hydrocarbons by oil field isolated bacterial consortium. African Journal of Biotechnology, 11(3): 650 .

[10] Abioye, O.P. (2011). Biological remediation of hydrocarbon and heavy metals contaminated soil, Soil Contamination, 7:127-142.

[11] Weston, A. and Balba, T. (2003). Bioaugmentation. Innovative Technology Group, 3(4): 1-2.

[12] Mbachu AE, Chukwura EI and Mbachu NA. (2016). Isolation and characterization of hydrocarbon degrading fungi from used (spent) engine oil polluted soil and their use for polycyclic aromatic hydrocarbons (PAHs) degradation. Universal Journal of Microbiology Research,4(1): 31-37. DOI:10.13189/ujmr.2016.040105 http://www.hrpub.org/

[13] Mbachu AE, Chukwura EI and Mbachu NA. (2017). Waste engine oil degrading potentials of indigenous fungi isolated from auto-mechanic workshops: impacts of heavy metals $(\mathrm{Zn}$ and $\mathrm{Pb})$ co-contamination and $\mathrm{pH}$. American Journal of Life Science Researches, 5(1): 6-7.

[14] Zajic, E. and Supplission, B. (1972). Emulsification and degradation of "Banker C" fuel oil by microorganisms. Biotechnology and Bioengineering, 14, 331-343.

[15] APHA (1998). Standard methods for examination of water and wastewater, $20^{\text {th }}$ Edn. Washington, D.C. American Public Health Association.

[16] Olajide, P.O. and Ogbeifun, L.B. (2010). Hydrocarbon biodegrading potentials of a Proteus vulgaris strain isolated from Fish samples. American Journal of Applied Sciences, 7 (7): 922-928.

[17] Akpoveta, O.V., Egharevba, F., Medjor, O.W., Osaro, K.I. and Enyemike, E.D. (2011). Microbial degradation and its kinetics on crude oil polluted soil. Research Journal of Chemical Sciences, 1(16): 8-14.

[18] Barnett, H.L. and Hunter, B.B. (2000). Illustrated genera of imperfect fungi. 4th edn. Laskin, A.I. and Lechevalier, H.A. (eds). CRC Press, West Palm Beach, Florida, pp 1- 197.

[19] Watanabe, T. (2002). Morphologies of cultured fungi and key to species. In: Pictorial atlas of soil and seed Fungi. 2nd edn. Haddad, S., Dery, E. Norwitz, B.E. and Lewis, R (eds). CRC Press LLC, 2000 N.W. Corporate Blvd., Boca Raton, Florida 33431. Pp 1- 486.

[20] Abioye, O. P., Agamuthu, P. and Abdul Aziz, A.R. (2012). Biodegradation of used motor oil in soil using organic wastes amendments. Biotechnology Research International, 2012: $1-8$.

[21] Yeung, P. Y., Johnson, R. L. and Xu, J. G. (1997). Biodegradation of petroleum hydrocarbons in soil as affected by heating and forced aeration. Journal of Environmental Quality, 26, 1511-1576.

[22] April, T.M., Foght, J.M. and Currah, R.S. (2000). Hydrocarbon-degrading filamentous fungi isolated from flare pit soils in Northern and Western Canada. Candian Journal of Microbiology, 46(1): 38-49.

[23] Sepahi, A.A., Dejban, G.I., Emami, M. and Nakhoda, A.M. (2008). Isolation and characterization of crude oil degrading Bacillus spp. Iranian Journal of Environmental Health Science and Engineering, 5: 149154. 
[24] Vanishree, M., Thatheyus, A.J. and Ramya, D. (2014).

Biodegradation of petrol using the Fungus Penicillium sp. Science International, 2 (1): 26-31.

[25] Obire, O. and Nwaubeta, O. (2002). Effects of refined petroleum hydrocarbon on soil physicochemical and bacteriological characteristics. Journal of Applied Sciences and Environmental Management, 6 (1):39-44.

[26] Akoachere,J.T.K., Ahenji, T.N., Yongabi, F.N., Nkwelong, G. and Ndip, R.N. (2008). Lubricating oildegrading bacteria in soils from filling stations and auto-mechanic workshops in Bueau, Cameroon: occurrence and characteristics of isolates. African Journal of Biotechnology, 7(11): 1700-1706.

[27] Larik, I.A., Qazi, M.A., Kanhar, A.R., Mangi, S., Ahmed, S., Jamali, M.R. and Kanhar, N.A. (2016).
Biodegradation of petrochemical hydrocarbons using an efficient bacterial consortium: A2457. Arabian Journal of Science and Engineering, 41: 2077-2086.

[28] Ghazali, F.M., Rahman, R.N.Z.A., Salleh, A.B. and Basri, M. (2004). Biodegradation of hydrocarbons in soil by microbial consortium. Internati onal Biodeterioration and Biodegradation, 54: 61-67.

[29] Alisi, C., Musella, R., Tasso, F., Ubaldi, C., Manzo, S., Cremisini, C. and Sprocati, A.R. (2009). Bioremediation of diesel oil in a co-contaminated soil by bioaugmentation with a microbial formula tailored with native strains selected for heavy metals resistance. Science of the Total Environment, 407: 3024-3032.

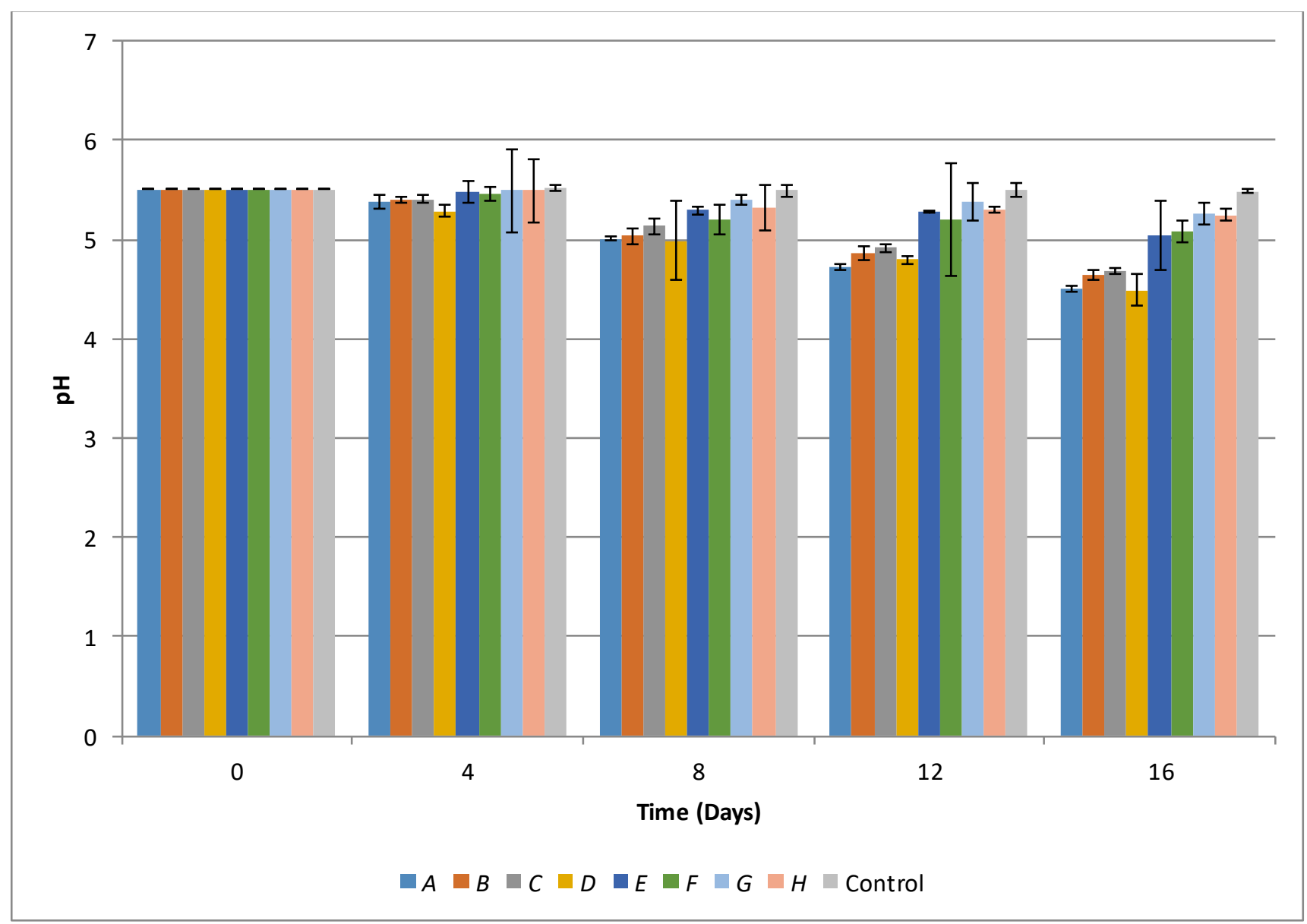

Fig..1: Changes in $\mathrm{pH}$ with time during utilization of UEO by the isolates. Bars indicate the average of triplicate samples while the error bars shows standard deviation $( \pm S D)$. 


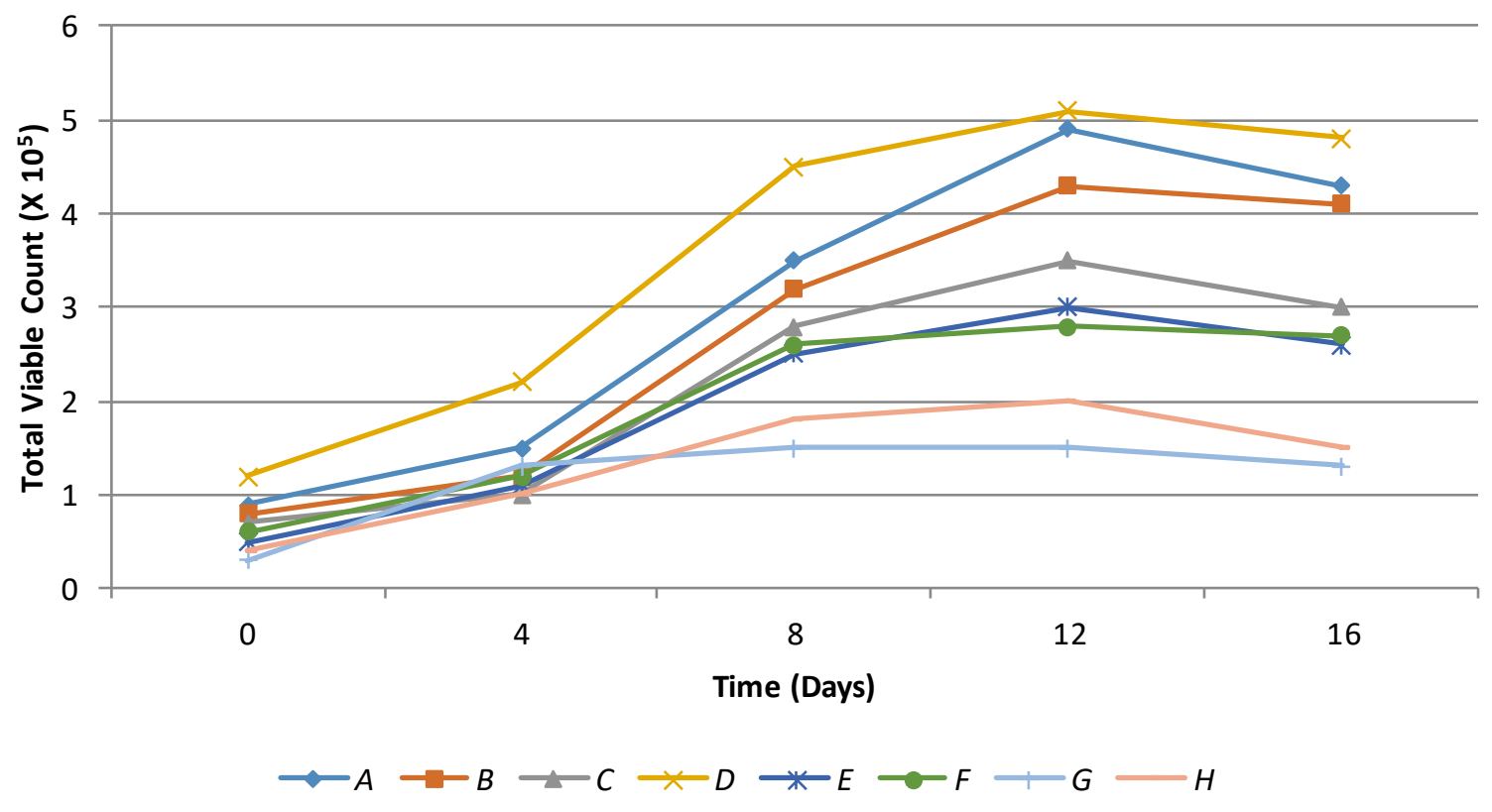

Fig.2: Changes in total viable count with time during utilization of UEO by the isolates.

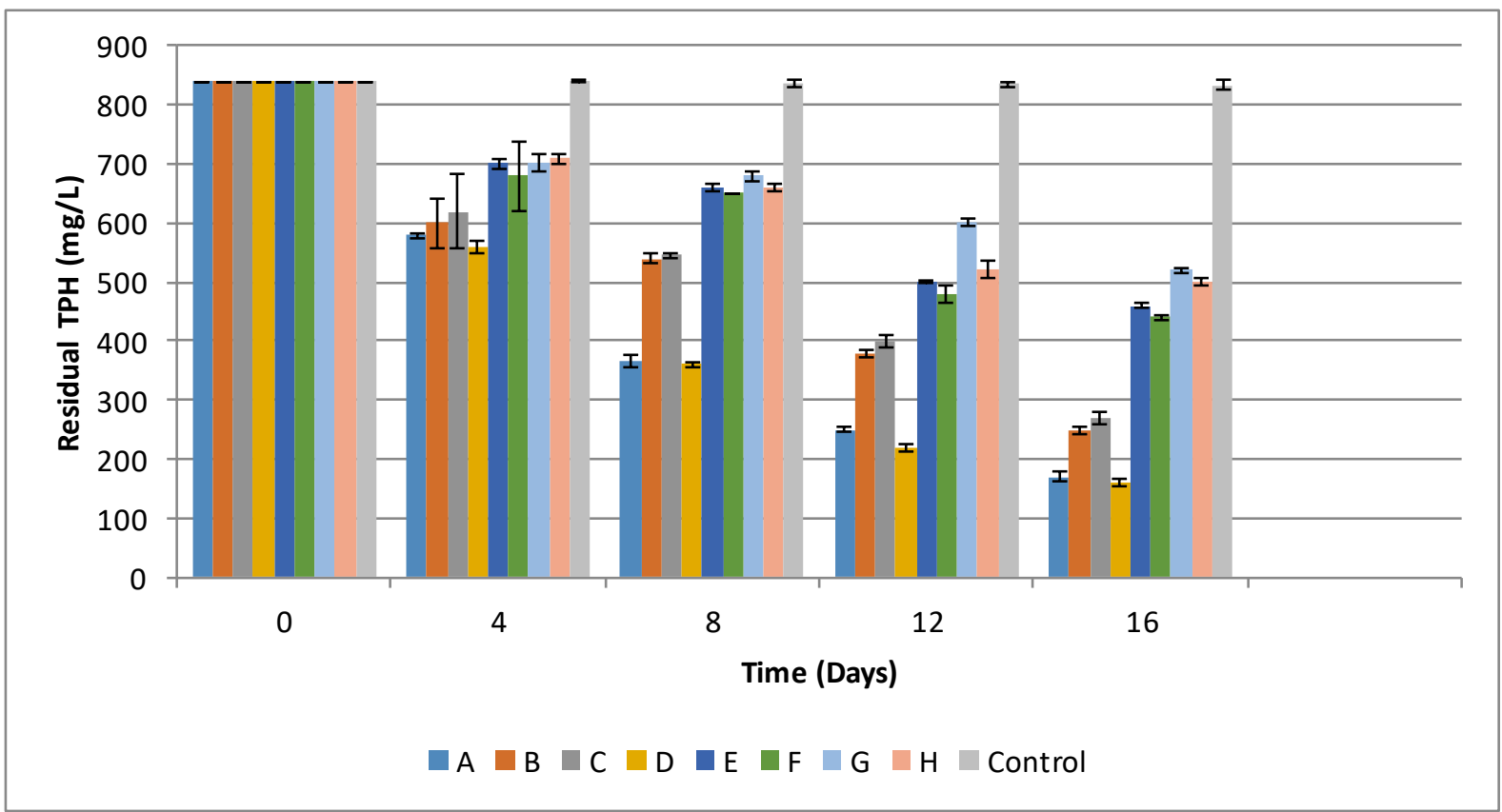

Fig.3: Changes in total petroleum hydrocarbon with time during utilization of UEO by the isolates. 


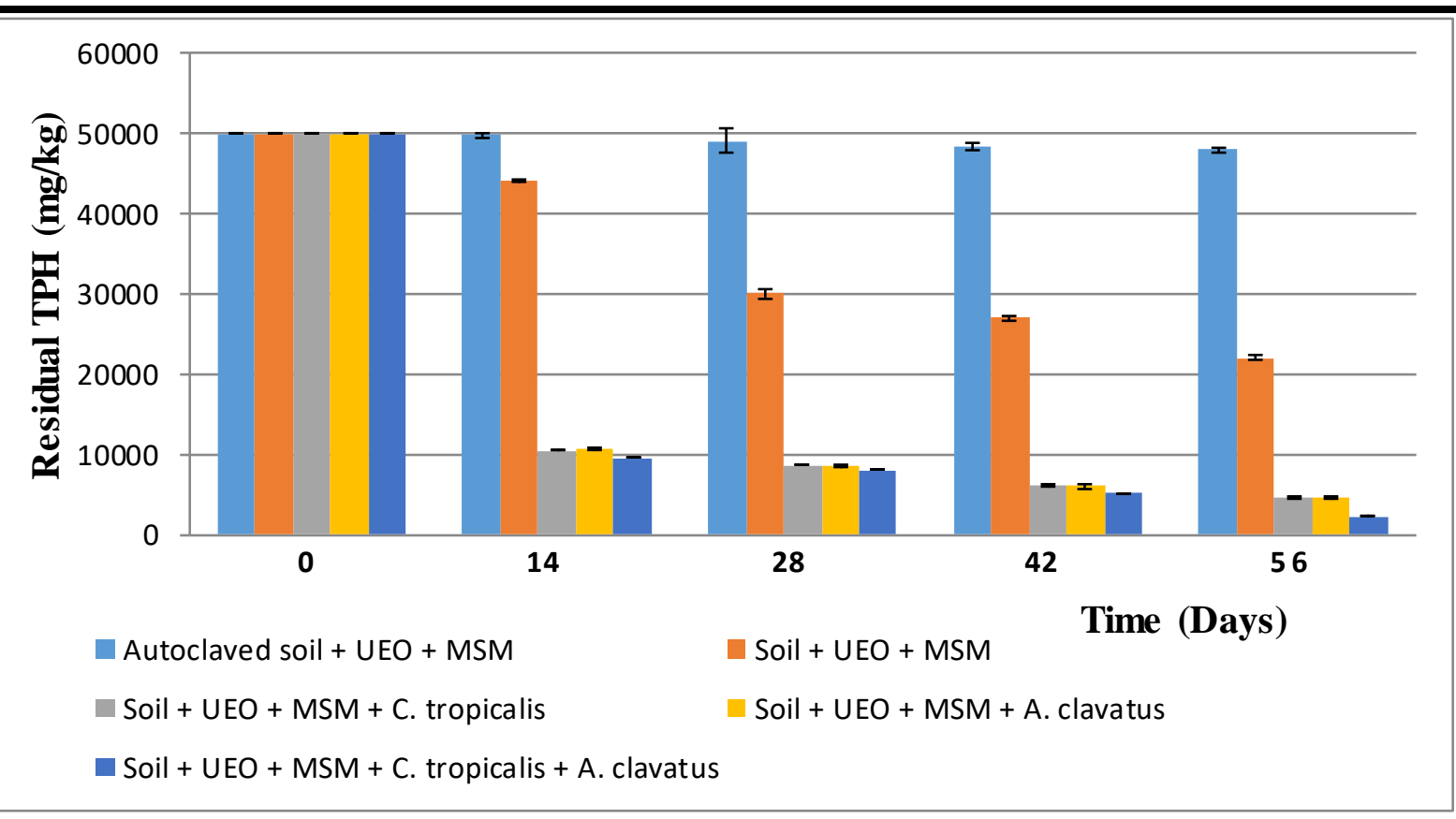

Fig.4: Residual total petroleum hydrocarbon in soil during bioremediation

Table.1: Net percentage (\%) loss of TPH in soil during bioremediation

\begin{tabular}{llllll}
\hline Microcosm set up & \multicolumn{5}{c}{ Time (days) } \\
\cline { 2 - 6 } & 0 & 14 & 28 & 42 & 56 \\
\hline A & 0 & $67.27 \pm 0.13$ & $43.60 \pm 0.14$ & $43.27 \pm 2.23$ & $36.27 \pm 0.96$ \\
B & 0 & $66.86 \pm 0.26$ & $43.79 \pm 0.72$ & $43.48 \pm 0.69$ & $36.46 \pm 0.44$ \\
C & 0 & $69.07 \pm 0.76$ & $44.81 \pm 0.44$ & $45.34 \pm 0.39$ & $41.25 \pm 0.32$ \\
\hline
\end{tabular}

$\mathrm{A}=\mathrm{Soil}+\mathrm{UEO}+\mathrm{MSM}+$ C. tropicalis, $\mathrm{B}=\mathrm{Soil}+\mathrm{UEO}+\mathrm{MSM}+$ A. clavatus, $\mathrm{C}=\mathrm{Soil}+\mathrm{UEO}+\mathrm{MSM}+$ C. tropicalis + A. clavatus. Net $\%$ loss $=\%$ loss of TPH in inoculated soil microcosm - \% loss of TPH in uninoculated soil microcosm (control 1).

Table.2: Biodegradation rate and half-life of TPH in oil-polluted soil

\begin{tabular}{lll}
\hline Microcosm set up & Biodegradation constant $(k)$ day $^{-1}$ & Half-life $\left(t_{1 / 2}\right)$ days \\
\hline A & $0.2295 \pm 0.013^{\mathrm{b}}$ & 3.02 \\
B & $0.2303 \pm 0.009^{\mathrm{b}}$ & 3.01 \\
C & $0.3013 \pm 0.029^{\mathrm{b}}$ & 2.30 \\
D & $0.0553 \pm 0.004^{\mathrm{b}}$ & 12.53
\end{tabular}

$\mathrm{A}=\mathrm{Soil}+\mathrm{UEO}+\mathrm{MSM}+$ C. tropicalis, $\mathrm{B}=\mathrm{Soil}+\mathrm{UEO}+\mathrm{MSM}+$ A. clavatus, $\mathrm{C}=\mathrm{Soil}+\mathrm{UEO}+\mathrm{MSM}+$ C. tropicalis + A. clavatus, D = Soil + UEO + MSM. Values followed by letter b are different significantly at $\mathrm{P}<0.05$ level. 